\title{
A System Dynamics Model for Construction Method Selection with Sustainability \\ Considerations
}

Gulbin Ozcan-Deniz and Yimin Zhu

\begin{abstract}
Construction projects have project conditions that change over time, like the availability of resources. These changes have the potential to influence the selection of construction methods, which in turn significantly affects the chance of successfully accomplishing project objectives, such as the time of completion, cost, and sustainability. In addition, project conditions are dynamic, and their impact on construction methods and project objectives are difficult to predict intuitively. Therefore, there is a need for an analytic procedure to understand the impact of different project conditions on the decision-making process of construction professionals. This analytical procedure will better inform construction professionals during the selection of construction methods. The authors applied systems dynamics to simulate and analyze the changing project conditions and their influence on the selection of construction methods when decision-makers are constrained by time, cost and environmental impact objectives. Two highway case studies were considered to demonstrate the effectiveness of the system dynamics model. The results of the case studies suggest that the proposed systems dynamics model has the potential to effectively simulate decision-making processes in construction under changing project conditions while outputting the most feasible construction methods. Furthermore, the study shows that project conditions have an impact on the flow of construction processes.

Keywords: system dynamics, construction method selection, decision-making, sustainability.




\section{Introduction}

The presence of multiple and often conflicting objectives in construction has resulted in significant studies in the area of project optimization (El-Rayes \& Kandil, 2005). Traditionally, researchers have focused on project-specific objectives, such as time, cost, safety, quality, and sustainability, to complete a project successfully within the constraints set by external factors (Kandil et al., 2010). However, recently, sustainability has increasingly become a new criterion of project success (e.g., Ofori, 1992; Selih, 2007).

The inclusion of sustainability as a new project performance indicator, which is often expressed in terms of environment impacts, has led to the requirement of a better understanding of project sustainability and its impact on the performance of construction projects (Cole, 2005). Project conditions, a collective term for describing project external factors, play a significant role in influencing both project sustainability considerations and project performance (Ozcan-Deniz \& Zhu, 2015). For example, project condition changes, such as the unit cost of resources or market conditions affecting bidding procedures, were rated as "high to very high" risk items (Skorupka, 2008). It is challenging to predict the behavior of project conditions because they change within the entire context of a construction project. Therefore, it is critical to have a comprehensive analytic procedure that connects project conditions (i.e., external factors) and project objectives (i.e., internal considerations). The connection will help better understand the impact of different project conditions on the decision-making processes of construction professionals regarding the impact of construction method selection on project objectives, such as time, cost and environmental impacts (TCEI).

Although construction professionals often have many alternative construction methods from which to choose, due to the complexities involved in foreseeing the impact of the 
alternatives on project objectives, some alternatives are often ignored during construction planning. It is common for construction professionals to choose a construction method based on previous experience, which potentially misses an opportunity to apply a better construction method. Previous studies have developed analytic approaches to help solve such a problem. For example, different types of artificial intelligence (AI) systems, such as expert systems, artificial neural networks (ANNs), and support vector machines (SVMs), were studied for use in the selection of a construction method. However, these approaches showed limitations, such as lacking self-learning and having a time-consuming acquisition process (Shen et al., 2005).

Thus, the aim of this research is to determine a comprehensive approach for analyzing changing project conditions and their impact on TCEI objectives, i.e., an approach that also helps decision-makers select the most appropriate construction methods (Tsai et al., 2013). System dynamics (SD) modeling, a method that can be used to "select the most suitable method for a given purpose and objective" (Lorenz \& Jost, 2006), was found to be successful in solving complex system problems (e.g., Sterman, 2000; Sahin et al. 2015). Therefore, the authors propose a SD model to establish connections between project conditions and TCEI objectives to study the selection of construction methods. The proposed SD model and the simulation process are demonstrated using two case studies that share the same construction method alternatives for three highway construction activities: milling, paving, and laying the friction course.

The authors organized the paper into four parts. In the first part, the authors discuss the state-of-the-art knowledge regarding decision-making with multi-agents and SD modeling. In the second part, the authors explain the proposed SD model in detail. The third part contains the description of the two case studies and a validation of the proposed SD model using the case studies. The final part includes conclusions and recommendations for future studies. 


\section{Overview of Multi-Agent Decision-Making and System Dynamics}

There are two major technical pieces involved in this research: a multi-agent decisionmaking component and the SD model. The multi-agent decision-making component, which is part of the SD model, simulates a decision process for selecting construction methods based on different project conditions. The SD model provides the overall architecture of this research.

\subsection{Decision-Making with Multi-Agent Systems}

In general, an agent can be defined as anything that can perceive its environment through sensors and can act through effectors (Russell \& Norvig, 2002). Multi-agent systems (MAS) are defined as a group of agents that attempt to maximize their own effectiveness while cooperating with other agents to achieve the desired objectives (Jennings et al., 1999). Agents in this study are modeled as project parties who determine the most appropriate construction operations to deliver projects.

Agents in the life cycle of construction projects include parties for both the design and construction phases. Different researchers have categorized construction parties in different manners. For example, in the MASCOT system (Ren \& Anumba, 2002), agents were limited to clients, contractors and engineers in the implementation phase; in contrast, Ugwu et al. (2005) defined project agents as also including client and design team agents (such as sub-contractors, construction engineers, and manufacturers). Alternatively, Xue et al. (2005) listed construction supply-chain agents as owners, general contractors, and designers together with sub-agents, such as sub-contractors and suppliers. Thabrew et al. (2009) considered agents to be contactors, local authorities, housing authorities, and manufacturers in life cycle assessment (LCA). Li et al. 
(2010) summarized agents in supply-chains as raw material suppliers, component suppliers, manufacturers, and retailers.

In summary, the decision process of parties at the design and construction phase can be modeled using MAS, which allows for the integration of decision-making with other construction modeling and simulation applications.

\subsection{Concept of Systems Dynamics, Modeling and Applications}

System dynamics (SD), "the investigation of the information-feedback character of industrial systems and the use of models for the design of improved organizational form and guiding policy" (Forrester, 1961), is a method for studying and managing complex systems (e.g., Forrester, 1985; Sterman, 2000). The concept combines the theory, methods, and philosophy required to analyze the behavior of complex systems and understand changes of system behavior over time (Forrester, 1994).

In general, SD models have three types of elements: (1) stock elements (state variables);

(2) flow elements; and (3) auxiliary variables and constants (Garcia, 2006). These elements permit the simulation of changes over time and the feedback of information (Richardson \& Pugh, 1981). Stocks, flows, and feedback loops are the basic elements to model the flow of work and resources through a project for the cause and effect analysis (Ogunlana et al., 2003).

A typical SD model structure includes project features, a rework cycle, project control feedbacks, and ripple and knock-on effects. Project features represent the development tasks or work packages, as they flow through a project (Lyneis et al., 2001). A rework cycle shows the iterative flow of work packages with respect to time. Several rework structures have been developed (e.g., Ford \& Sterman, 1998) and applied to explain different problems (e.g., Ford \& 
Sterman, 2003) in the literature. Feedback loops are used to control a project's performance. For example, Lyneis \& Ford (2007) used "Add People," "Work More," and "Work Faster/Slack Off" feedback loops to meet a project deadline. Ripple and knock-on effects are side effects that are caused by actions taken to close a gap between project performance and targets.

There are many SD applications in the literature, including work in construction project management (Table 1).

Table 1 System dynamics as applied in project management.

\section{Model Development}

\subsection{Overview of the SD Model for Construction Method Selection}

The authors model a construction system using two sub-systems, a decision-making and a project sub-system, as shown in Fig. 1. The decision-making subsystem simulates a decisionmaking process of selecting the most feasible construction method (CM) under the impact of changing project conditions. In this study, project conditions are considered external factors that can influence the decision-making of involved parties and their choice of construction methods. Therefore, they are included as one of the main parameters in the decision-making sub-system.

Fig. 1. Conceptual model as created for the construction system.

The project sub-system contains models of the resources and the processes related to a project and includes the calculation procedure of TCEI. The parameters used by the project subsystem include the project objectives, time, cost and environmental impacts of the CMs. All of these parameters constrain the selection of the CMs. The project sub-system reflects the 
properties of each project and uses different $\mathrm{CM}$ alternatives that are selected by the decisionmaking sub-system to calculate the TCEI values. Using this method, the TCEI values are calculated for different scenarios of project conditions, and the optimum one is selected based on TCEI objectives. The selection of TCEI values then allows for the selection of the most feasible CM.

In addition to the two sub-systems, the SD model includes a boundary, which is elaborated around the decision-making and project sub-systems. The boundary includes the components that are necessary to generate different scenarios in construction projects and enable the decision-making and project elements to perform the $\mathrm{CM}$ selection. The components include project conditions, multi-agents, construction methods (with possible alternatives), and TCEI values calculated within the system. This research is mainly focused on the integration of two sub-systems, particularly on the details of the project sub-system. The details of the decisionmaking sub-system were discussed in a previous study (Ozcan-Deniz \& Zhu, 2011) and are outside the scope of this paper; however, a brief summary of the decision-making process is provided in the next section.

\subsection{Development of the Decision-Making Sub-System}

As mentioned above, changing project conditions affect the decision-making processes of contractors and owners. In a previous study regarding highway construction (Ozcan-Deniz \& Zhu, 2011), the authors identified seven project conditions (Table 2). These conditions are the basis for establishing IF-THEN rules in multi-agent decision-making modeling. For example, adverse financial issues and market conditions influence owner's decisions and subsequently 


\begin{abstract}
have an indirect impact on the decision-making process of contractors. Other factors may directly affect contractor's decisions on the selection of construction methods.
\end{abstract}

Table 2 Project conditions as defined in the decision-making process.

These project conditions are coded as $C_{i}$ in the sub-system, where $C$ denotes conditions and $i$ denotes a sequential number of a condition from 1 to 7 (Table 2). Each condition $i$ is described by its importance weight $\left(I W_{i}\right)$ and probability of occurrence $\left(P_{i}\right)$. For example, $C_{1}$ (Condition 1$)$ is affected by the values of $I W_{1}$ and $P_{1}$ (Equation 1 ). The $I W$ values are obtained from expert inputs through interviews, whereas the $P$ values are randomly generated. The randomize function in MS Excel was used to obtain a probability value between 0 and 1 .

$$
C_{i}=\left\{I W_{i}, P_{i}\right\}
$$

Equation 1

The decision-making mechanism of CM selection is modeled using three CM indicators: material selection $(M)$, equipment selection $(E)$, and stabilizing additive selection $(S)$. CM alternatives for different project conditions are based on combinations of these CM indicators. Thus, a CM alternative is expressed using Equation 2, where $n$ denotes the $n$th number of alternative and $i, j$, and $k$ denote different types of material, equipment, or stabilizing additive, respectively.

$$
C M_{n}=\left\{M_{i}, E_{j}, S_{k}\right\}
$$

Equation 2

Through structured interviews with experts in the Florida Department of Transportation (FDOT), the authors obtained information regarding the relative importance of project conditions on material, equipment, and stabilizing additive selection for different $\mathrm{CM}$ alternatives. The experts also evaluated different construction methods and reviewed the material and equipment options to create compatible matching pairs for this study. 

additive selection) have different $I W$ values, the coding of each $I W$ has a prefix that denotes a particular CM indicator. For example, for material selection, the importance weight of the first condition is coded as MAT-IW-1; for equipment selection, the code for the same condition is EQUI-IW-1; and for stabilizing additive selection, it is $S T A B-I W-1$. Because the probabilities are the same for different CM indicators, they are only symbolized with the condition's number, i.e., $P_{l}$ for the first condition. Examples of material selection, equipment selection, and stabilizing additive scores, which are composed of probability and impact values for Condition 1, are given in Equations 3, 4, and 5. Next, Equations 6, 7, and 8 show how the material, equipment, and stabilizing additive selection scores are calculated for the decision-making process.

Material Selection for $C 1=" M A T-C 1 "=" M A T-I W-1 " * " P_{1} \quad$ Equation 3

Equipment Selection for $C 1=" E Q U I P-C 1 "=$ EQUIP-IW-1 $* " P_{1} \quad \quad$ Equation 4

Stabilizing Additive Selection for $C 1=\mathrm{STAB}-\mathrm{C}_{1}=\mathrm{STAB}-\mathrm{IW}-1 * " P_{1} " \quad$ Equation 5 Material Selection (M)Score

Equation 6

$$
\begin{aligned}
& =M A T-C 1 "+" M A T-C 2 "+\text { "MAT - C3" + "MAT - C4" } \\
& \text { + "MAT - C5" + "MAT - C6" + "MAT - C7" }
\end{aligned}
$$

Equipment Selection (E)Score

Equation 7

$$
\begin{aligned}
& =" E Q U I P-C 1 "+" E Q U I P-C 2 "+\text { "EQUIP }-C 3 " \\
& + \text { "EQUIP }-C 4 "+\text { "EQUIP }-C 5 "+\text { "EQUIP }-C 6 " \\
& + \text { "EQUIP - C7" }
\end{aligned}
$$

Stabilizing Additive Selection (S) Score

Equation 8

$$
\begin{aligned}
& =" S T A B-C 1 "+\text { "STAB-C2" + "STAB-C3" + "STAB } \\
& -C 4 "+\text { "STAB - C5" + "STAB - C6" + "STAB - C7" }
\end{aligned}
$$


In summary, the decision-making sub-system includes a reflection of how the owner and contractor agents make decisions considering the effect of seven conditions. The authors applied IF-THEN rules to model the reflection. First, for each project condition, a score was calculated by multiplying its relative importance weight and probability for all $\mathrm{CM}$ indicators (material selection, equipment selection, and stabilizing additive selection). Then, the decision-making was performed by using IF-THEN rules, where the IF part represents the CM indicators and the THEN part represents the selected construction method (Fig. 2).

Fig. 2 Flowchart to perform decision-making.

The CM selection function and the IF-THEN rules are given in Equation 9, 10, and 11. The values for the constants (e.g., $Y, Z$, and $K$ ) of different $i, j$, and $k$ are derived from the Analytical Network Process (ANP) analysis (Ozcan-Deniz \& Zhu, 2015). The constants (e.g., Y, $Z$, and $K$ ) are calculated from the previously mentioned equations as a sum of the effect of seven project conditions. Alternatively, $i, j$, and $k$ are numbers stating different types of material, equipment, or stabilizing additive. For example, $\mathrm{M}_{1}$ denotes the first material type, and so on. By using the given equations, the CM Selection control unit selects the most feasible construction operation based on the combination of material selection, equipment selection, and stabilizing additive selection values.

IF Material (M) Score $=Y$, THEN select $M i$, where $i \in[0,5]$.

Equation 9

IF $M x=M i \&$ Equipment Score $(E)=Z$, THEN select $E j$, where $j \in[0,2] . \quad$ Equation 10 
IF $M x=M i \& E x=E j \&$ Stabilizing Additive (S) Score $=K$,

Equation 11

THEN select $S_{k}$, where $k \in[0,2]$.

\subsection{Project Sub-System}

When a construction method is selected by a contractor under the influence of the project conditions, it is further analyzed by the project sub-system. In the project sub-system, the selected construction method is further decomposed into resources, including materials and equipment, through its indicators, as mentioned previously.

The calculations of time, cost and environmental impacts use both qualitative and quantitative data. In addition to qualitative information from the interviews, quantitative project data were collected from documents, such as plans, contracts (which include resource types and amount as well as fuel consumptions of equipment), schedules, and daily progress reports from FDOT projects. These data were used to create equations in the project sub-system and to calculate the TCEI values. In addition, information, such as the resource quantities, unit costs, activity durations, and fuel consumptions of equipment, was maintained in an MS Excel database to support the calculation of project time, cost and GHG for each activity. The details of this calculation process are discussed in the next section.

After the TCEI is calculated, the output is further input to the control units of the proposed SD model. The TCEI calculated under the influence of project conditions are compared with the target time, cost and GHG that were entered by users. The gap between the estimated and target TCEIs is used to determine the suitability of the selected construction method.

\subsection{Data Collection and Analysis for TCEI Calculations}


Three types of data (project durations, project cost and environmental impacts) were collected and processed before they were used in the SD model. The authors used MS Excel to store the data and calculate the TCEI. Next, the output of the MS Excel was linked to the project sub-system. Data in the form of plans, contracts (which include resource types and amounts as well as equipment fuel consumption), schedules, and daily progress reports were collected from the FDOT. Subsequently, the required information was identified through these data to calculate the TCEI values of alternative CMs. Project duration and cost data were derived using conventional scheduling and estimation methods. To implement the construction operations, schedules from the FDOT were analyzed to determine the duration of the three resurfacing activities: milling, paving, and laying the friction course. The duration of the alternatives was estimated using the schedules available to the authors or reports from the FDOT State Material Office.

The contractual documents obtained from FDOT, including unit costs and quantities of resources, were used to calculate the cost of the original construction methods. For construction method alternatives, the unit costs of different materials were obtained from the literature or public data sources.

The environmental impacts of materials and equipment were derived based on an LCA approach (EPA, 2006). LCA is described as the most sophisticated tool to consider and quantify the consumption of resources and the environmental impacts associated with a product or process (Curran, 1996). LCA considers not only the construction phase but also the remaining phases of building elements as well as the effects of different operations on the environment during all of the stages of a construction project. LCA has been used in the selection of materials and the utilization of alternative materials in the literature (Mladenovic et al., 2015). Thus, LCA 
is helpful for evaluating the environmental impacts of products and services from a "cradle to grave" perspective (Bengtsson, 2001). Environmental impacts can be calculated in different categories (e.g., Green House Gas (GHG) emissions, energy consumption, acidification, and pollutants to air and water) through the life cycle phases. In the scope of this paper, the calculation of environmental impacts was limited to GHG emissions.

Environmental impact data may require a significant amount of preparation, depending on the scope of the analysis. There are three types of sources for environmental impact data. The first is the database associated with an LCA software tool. For example, the ATHENA ${ }^{\circledR}$ Impact Estimator/EcoCalculator has a built-in lifecycle inventory for environmental impact assessment. This source is not applicable to this study because ATHENA did not have the required database for highway construction projects when this study was conducted. The second source is the lifecycle inventory (LCI) databases, e.g., the one developed by the National Renewable Energy Laboratory (NREL, 2012). The first and second sources are closely related because the ATHENA tools uses the NREL LCI database. However, the second source provides some flexibility for customization, when required. The third source is the literature. For example, EPA eGRID (EPA, 2011) provides data on the national average emissions by electricity consumption. The construction equipment and tools used by contractors typically consume fuel. EPA provides data regarding the environmental impacts of different types of fuel (EPA, 2009).

In this paper, data from the literature sources were used to determine the GHG emissions of different construction method alternatives. The LCI information from the literature was used to calculate the GHG emissions caused by the materials and equipment in highway projects. The quantity takeoff data were analyzed by using process, transportation, and landfilling inventory values to calculate the $\mathrm{GHG}$ ( $\mathrm{kg} \mathrm{CO}_{2}$ eq) of different materials. Published cases were used 
together with the quantities of materials to calculate the GHG emissions of different alternatives. In addition, the fuel consumption data for both the original and alternative construction methods were utilized to determine the environmental impact of the equipment.

For the original methods' GHG calculations, the data provided by the FDOT required further preparation. The equipment's gasoline and diesel consumption was available in the contract. The unit of measure of fuel consumption was in gallons. However, this information had to be converted to $\mathrm{kg} \mathrm{CO}_{2}$ eq to obtain the total $\mathrm{GHG}$ emissions for materials and equipment of a project. To convert these values, the types and quantities of gases released to the air by the consumption of gasoline and diesel fuel sources were determined, and the EPA LCI data were used. Next, these values were summed with the GHG obtained from the materials. Because the project conditions possessed different properties, the SD model selected different resource combinations. Different outcomes for the estimated time, cost and GHG were obtained according to whichever resource combination was selected.

The TCEI values of a project were calculated and compared with the target time, cost and GHG that were pre-set by users. The difference between the project and target TCEI values was used to as a criterion to select the construction methods. This analysis process affected the rework cycle (Fig. 3), which kept the SD simulation running until a threshold of the difference between the project and target TCEI was reached. Consequently, the cycle ran a feedback loop and decided when the simulation stopped. The simulation process is explained by the flowchart shown in Fig. 4. The application of the simulation on the case studies is explained in the next section.

Fig. 3 Rework cycle as run in the SD simulation. 
Fig. 4 Flowchart as created for the proposed SD model.

\section{Case Studies}

To demonstrate the application of the proposed SD model, the authors used two case studies of highway resurfacing projects, using GHG emissions as a proxy of environmental impacts. The major steps of the case studies include defining the highway construction operations; calculating the time, cost and GHG emissions; and performing SD simulation.

\subsection{Highway Construction Operations}

Highway resurfacing projects consist of core activities, such as milling the existing asphalt, placing asphaltic concrete, and placing the concrete friction course. The resurfacing operation is performed lane by lane. In a conventional method, existing asphalt is milled and then hauled by dump trucks for recycling. New asphaltic concrete can be a virgin or recycled mix. Asphalt compositions are different in terms of not only the amount of recycled concrete they have but also their temperature of mixing.

The two most widely accepted Hot Mix Asphalt (HMA) design methods are Marshall and Hveem (Bahia, 1993). Although the Marshall mix design method has been widely used by DOTs in the U.S., performance issues spurred the Strategic Highway Research Program (SHRP) to develop a performance-based asphalt binder and asphalt mix specifications (Roberts, et al., 2002). In addition, the development of new laboratory testing equipment and performance graded (PG) binder specifications and tests has resulted in Superpave (superior performing asphalt pavements) (Larsen, 2003). Whereas Superpave is an innovation of the HMA design method, another technology, Warm Mix Asphalt (WMA), handles the mixing process at a lower 
temperature than HMA does. WMA has been developed in Europe and implemented in the U.S. (Chowdhury \& Button, 2008).

In addition to the progress in asphalt mix design, equipment technology has evolved towards better performance in milling and placing asphalt. Hot In-Place (HIP) recycling technology is proposed to combine milling existing asphalt and placing asphaltic concrete in resurfacing projects. The new technology has a single unit for recycling existing pavement and mixing milled pavement with new paving materials. In this way, HIP eliminates the hauling and handling of recycled materials (Russell, et al., 2010).

The evolution of the equipment is based on not only the technology but also the type and use of fuel. Low-carbon or bio-fuels are promising strategies to reduce life cycle GHG emissions (EPA, 2009).

\subsection{Environmental Benefits of New Technologies}

In the scope of this paper, the environmental impact of construction methods is measured by GHG emissions, which is influenced by construction contractors' decisions. Construction contractors may influence GHG emissions by decisions such as fuel selection, equipment idling, electricity use, equipment maintenance, equipment selection, and material recycling (EPA, 2009). In terms of materials, different asphalt mixing methods have different outcomes in environmental impacts. For example, using a recycled mix in paving or performing Reclaimed Asphalt Pavement (RAP) reduces the demand for new materials, saves energy, and reduces carbon output (Huddleston, 2008). In a similar manner, WMA technology reduces fuel/energy consumption and decreases emissions and dust production (Chowdhury \& Button, 2008). Compared with HMA, WMA may lead to reductions of $24 \%, 18 \%$, and $10 \%$ in air pollution, 
fossil fuel consumption, and smog formation, respectively. Overall, WMA generates $15 \%$ less environmental impacts than HMA does (Hassan, 2009). As an emerging technology, HIP recycling consumes $15 \%$ less overall energy per ton laid down (CCE, 2005). Between the HMA and HIP technologies, HIP consumes 110-250 MJ less energy per ton than HMA does (Terrel \& Hicks, 2008).

Regarding fuel selection, replacing petroleum gasoline or diesel with biodiesel reduces GHG emissions by approximately $25 \%-65 \%$. Switching from petroleum diesel to biodiesel can save a significant amount of GHG emissions, such as 100\% (B100) or 20\% (B20).

\subsection{Construction Method Alternatives}

Based on the aforementioned discussion, the authors presented several construction method alternatives for highway resurfacing projects. The construction method alternatives are defined for the core activities, i.e., milling, resurfacing, and placing friction course. Various construction methods in terms of material, equipment, and technology selection resulted in 16 alternatives for the three activities (Table 3).

Table 3 Construction methods as defined for resurfacing project activities.

\subsection{Case Study 1 Details}

Case Study 1 is a resurfacing project from FDOT District 6 . The project includes milling the existing asphalt, placing the asphaltic concrete, and laying the concrete friction course. Originally, milling was performed using conventional equipment, and then the milled asphalt was hauled by dump trucks to be recycled. The original construction method is referred to as the existing method in this study. The differences between the original method and other alternatives, 
as listed in Table 3, were reflected by different types of materials, equipment, and stabilizing additive content of materials.

In addition, time, cost and GHG emissions were calculated for different types of construction methods, as shown in Table 4. The original project duration was taken as stated in the bar chart received in the data package. The durations for alternative construction methods, except the HIP, were estimated based on the original duration. For HIP mix and equipment, the duration was estimated by using the published sources from FDOT. The original cost information was available in the contract, with details such as quantities and unit costs of resources. The unit costs for alternatives were estimated.

Table 4 Time, cost and environmental impact as calculated for Case Study 1.

\subsection{Case Study 2 Details}

Case Study 2 is a resurfacing project from FDOT District 4 . The project includes the same activities as Case Study 1: milling the existing asphalt, placing asphaltic concrete, and laying the concrete friction course. However, in Case Study 2, different resource utilization plan and construction methods were used instead of the existing method. In the original set of construction methods, Superpave asphalt was used for paving. Before the pavement of the new asphalt, the old asphalt was milled with conventional equipment. The milled asphalt was hauled by dump trucks to be recycled. For the friction course layer, FC-9,5 was used as the base material. The activities and the construction method alternatives of Case Study 2 are consistent with those of Case Study 1 (Table 5).

Table 5 Time, cost and environmental impact as calculated for Case Study 2. 
The same set of calculations used in Case Study 1 was used in Case Study 2. The differences among the alternatives were reflected by different types of materials, equipment, and stabilizing additive content of materials. The model was simulated with different properties of the project conditions, and the model selected different resource combinations for various probabilities. Different outcomes for the estimated time, cost and GHG emissions were obtained according to whichever resource combination was selected. These resource combinations and outcomes are further analyzed in the following section.

\section{Analysis and Results}

The analysis of the SD model was conducted with the aim of observing the effectiveness of the model in simulating both decision-making and project systems by using Vensim. A snapshot of the Vensim screen during the simulation of the proposed SD model with a random set of probabilities is shown in Fig. 5.

Fig. 5. Vensim screen as seen during the simulation.

The results from Vensim in the form of $C M\left(M_{i}, E_{j}, S_{k}\right)$ are further decoded into the construction methods and their corresponding resource types. For example, $C M\left(M_{3}, E_{1}, S_{2}\right)$ denotes the selection of virgin-WMA for the resurfacing activity, diesel equipment for the milling activity, and the FC-9,5 layer for the friction course activity. For each set of different probabilities created randomly, similarly formatted resource results were obtained.

In addition, the simulation provided TCEI output based on the resource types selected for the project. An example set of the time, cost, and GHG results is shown in Table 6. The units of 
the objectives are days for time, dollars for cost and $\mathrm{kg} \mathrm{CO}_{2}$ eq for $\mathrm{GHG}$ emissions. To calculate the gap between the target and simulated TCEI values, the target time, cost, and GHG values were entered. Considering the calculated TCEI values, the target values were set to be smaller than the minimum of the time, cost, and GHG values. The aim was to simulate the SD model until it approached the minimum TCEI values. Therefore, the target time was set as 20 days (the minimum was 22 ), the target cost was set as $\$ 1,300,000$ (the minimum was $\$ 1,356,935$ ), and the target GHG was set as 2,700,000 $\mathrm{kg} \mathrm{CO}_{2}$ eq (the minimum was 2,704,097 $\mathrm{kg} \mathrm{CO}_{2}$ eq).

Table 6 Time, cost, and GHG results given as an example set.

Different probabilities resulted in different resource utilization plans and different project TCEI values. An example set of randomly formed probabilities and their TCEI results for Case Study 1 is shown in Table 7. An infinite number of similar sets of probabilities can be entered into the proposed SD model. Table 7 includes probability values (P-1-P-7) as inputs to the SD model. Each probability matches with a project condition and defines its probability of occurrence as a percentage. For example, P-1 represents the probability of occurrence of $\mathrm{C}_{1}$, adverse financial issues of owner. Similarly, P-2 denotes the probability of occurrence of $\mathrm{C}_{2}$, adverse market conditions (affecting owner). The logic is the same for all seven conditions and their probabilities. The probabilities are then multiplied by the relative importance of their related conditions, and the score for material, equipment, and stabilizing additive selection is calculated by using all of the project conditions. The scores are further used to select the most feasible construction method.

Table 7 Input and output values as resulted from Case Study 1. 


\section{Model Testing and Validation}

To test and validate the SD model, three types of tests, as suggested by Sterman (2000), were used. The first test is to determine the structural similarity of the model to the actual system, the second test is to check reasonable behavior over a wide range of input values, and the third test is to compare the model behavior with actual system behaviors. Because the proposed model is based on previously validated project models and literature, the model's structural similarity matches an actual system. For the second test, the model is checked for reasonable behavior over a wide range of input values. During simulation, the model behavior remains reasonable across changes in the individual probability values and with extreme input values, as shown in Table 7 (Ozcan-Deniz \& Zhu, 2012). In their study, Ozcan-Deniz \& Zhu (2012) discussed the feasibility of using SD modeling to simulate and analyze various construction methods. The aim was to determine whether SD modeling has the potential to simulate and analyze various construction methods. The results showed that the application of SD was technically feasible and potentially led to better resource utilization plans to achieve environmentally conscious construction. Considering these results, the authors decided to proceed with the SD model discussed in this paper to improve the construction method selection. In this study, an analytical procedure was developed to simulate and analyze changing project conditions and their influence on the selection of construction methods when decision-makers are constrained by TCEI objectives. A thorough analysis was performed to examine the impact of changing project conditions on the decision-making processes. Finally, the proposed model was tested for validation. 
Simulations using extreme parameter values, including the simulations with no (zero) and maximum probabilities, were run for all project conditions. In the case where all probabilities were $0 \%$ (Trial 19), there was no negative change regarding project conditions. This case was referred to as the best-case scenario. In the case where all probabilities were $100 \%$ (Trial 20), all negative changes regarding the project conditions occurred. This case was referred to as the worst-case scenario.

The same calculation steps were also applied to Case Study 2 to determine the effectiveness of the proposed model. First, the proposed SD model was simulated by using different probabilities of project objectives. The same probabilities that were formed randomly for Case Study 1 were used in Case Study 2. For example, the probabilities of Trial 14 was input to the model and then used for the simulation in Case Study 2. The results gave the exact resource combination as that in Case Study 1, i.e., $\mathrm{CM}\left(\mathrm{M}_{3}, \mathrm{E}_{1}, \mathrm{~S}_{2}\right)$. In addition, Case Study 2 was simulated for the best-case scenario (where all probabilities are 0\%) and the worst-case scenario (where all probabilities are 100\%). The CM combinations obtained for the best-case and worst-case scenarios were the same as those of Case Study 1. For example, both cases selected the HIP Mix (Marshall+milled) with biodiesel equipment and the FC-5 layer for the best-case scenario and the Virgin-WMA with conventional equipment and the FC-9,5 layer for the worstcase scenario. This observation shows the consistency of the results in both case studies.

The model's behavior for typical and extreme conditions is evaluated for the third test. When the same probabilities are input to different case studies (e.g., Trial 14), they output the same resource combinations as optimal, which indicates the behavioral similarity of the proposed system to actual system behaviors. The similarity of the CM selected results under the same probability inputs and when two different case studies are simulated shows the consistency of the 
results as well as the effectiveness of the proposed SD model. Note that the original construction methods used for Case Study 1 and Case Study 2 were different. Although there was a difference in the resources of the friction course activity, the original set did not create any difference in their results. Because the inputs for changing project conditions defined the most feasible construction method, the same construction methods were selected under similar scenarios. The influence of changing project conditions was reflected through various scenarios, and the selected CM was the one that outperformed all other methods, including the original one. In both case studies, the selected CM performed better than the original one under the influence of changing project conditions because the suggested CM considered the interrelations between the decision-making parameters and the relative importance weights of TCEI objectives. In addition, the changes in probabilities and relative importance weights of project conditions were successfully reflected in the CM selection and TCEI calculation in the model. This makes the proposed SD model even more successful because it can generate sensible decisions and select the most suitable CMs in a dynamic environment, similar to its real-world applications in construction. The results of these tests show the success of the decision-making model to characterize agent decisions by using multi-agents and IF-THEN rules.

\section{Conclusions}

The use of the SD model to understand the impact of different project conditions on the decision-making of construction professionals represents a new method to analyze time, cost and environmental impact objectives simultaneously. The model showed its potential to model a typical construction system with different types of resources and effectively analyze the process 
of construction method selection under changing project conditions and multiple project objectives.

The potential and effectiveness of the model was further demonstrated in two case studies of highway construction, where the authors applied the SD method to evaluate the environmental performance of highway projects. The results of the case studies show that the SD model consistently selects the most feasible construction method for typical and extreme construction conditions. In both cases, the model selected the same construction methods for the best-case and the worst-case scenarios. The results provided by the SD model also showed a similar structure and behavior of an actual construction project system, including changing project conditions due to dynamic construction systems. Therefore, the successful reflection of dynamic construction conditions in the model enables decision-makers to make a more educated decision regarding the suitability of construction methods.

The model has the potential to improve the process of construction method selection through analysis of the impact of changing project conditions and decision-making processes. For practical applications, the simulation can be used to reduce the decision-making time and environmental impacts while simultaneously optimizing the duration and costs of construction projects. Because of its capability to handle both project conditions and TCEI objectives, the SD model has great potential to help decision-makers and construction practitioners improve the chances of successfully completing the project objectives in the event of changing construction project conditions, such as unavailability of materials. The SD model also has potential for use in real-world applications. For example, in the case studies on highway resurfacing, when the decision-makers are challenged by the changes in project conditions, the SD model provides project outcomes with various construction methods, allowing for a more educated CM selection. 
Despite the successful application of the SD model, the current model is limited by the lack of a common technical platform, where project conditions and project objectives can be analyzed simultaneously. To address this problem, future work can involve the creation of a model in a shared environment, where all user inputs, selections, and outputs of the system will be stored in a single setting. This environment can be accomplished by creating a computerbased environment that can be used for both the SD-specific and standard mathematical functions. Another limitation of the model is the input data. The parameters of this model are limited to the data collected from highway construction projects. However, the model can be extended when data from other types of projects become available. Because the resources in the model are flexible, the highway-related resources can be replaced with building construction ones to simulate building projects. Future work can also expand the project system to include project objectives, such as project quality and safety, in addition to the customary objectives of time, cost and environmental impact. Additional objectives would enhance the feedback mechanism of the decision-making system such that many more factors can be considered for CM selections.

Finally, though SD models have been applied widely in academic research to solve different types of project management problems, as shown in Table 1, the practicality of SD models in general requires further investigation on a case-by-case basis. On the one hand, system dynamics models are typically deployed to solve complex problems; on the other hand, avoiding unnecessary complexities in an SD model helps improve the practicality of the model. In this study, the practicality of the proposed model will require further validation.

\section{Acknowledgements}


The authors gratefully acknowledge the financial support provided by the National Science Foundation (NSF) under the NSF award No. \#1000136. The views and opinions expressed in this paper are those of the authors and do not necessarily reflect the views and opinions of the National Science Foundation.

The authors also thank the FDOT for sharing their insight and expertise that greatly assisted the research effort.

\section{References}

Bahia, H. U., 1993. Bibliographies for physical properties of asphalt cement, SHRP-A-626, Washington, DC.: National Research Council.

Bengtsson, M., 2001. Weighting in practice: implications for the use of life-cycle assessment in decision making. Journal of Industrial Ecology, 4(4), pp. 47-60.

Bousquet, F. \& Le Page, C., 2004. Multi-agent simulations and ecosystem management: a review. Ecological Modelling, Volume 176, pp. 313-372.

Browning, T. R., Fricke, E. \& Negele, H., 2006. Key Concepts in Modeling Product Development Processes. Systems Engineering, 9(2), pp. 104-128.

CCE, 2005. Road Rehabilitation Energy Reduction Guide for Canadian Road Builders, Ontario: Natural Resources Canada.

Chowdhury, A. \& Button, J. W., 2008. A Review of Warm Mix Asphalt, College Station, TX: s.n.

Cole, R., 2005. Building environmental assessment methods: redefining intentions and roles. Building Research and Information, 35(5), pp. 455-467.

Curran, M. A., 1996. Environmental Life-Cycle Assessment. NY: McGraw-Hill.

El-Rayes, K. \& Kandil, A., 2005. Time-cost-quality trade off analysis for highway construction. Journal of Construction Engineering and Management, 131(4), pp. 477-486.

EPA, 2006. Life Cycle Assessment: Principles and Practice, Cincinnati, OH: EPA.

EPA, 2009. Potential for Reducing Greenhouse Gas Emissions in the Construction Sector, Washington, DC: s.n. 
EPA, 2011. The Emissions \& Generation Resource Integrated Database (eGRID), Washington, D.C.: EPA.

Ford, D. N. \& Mahieu, L. A., 1998. Operationalising the Resource-Based View of the Firm. Quebec, s.n.

Ford, D. N. \& Sterman, J. D., 1998. Dynamic modeling of product development processes. System Dynamics Review, 14(1), pp. 31-68.

Ford, D. N. \& Sterman, J. D., 2003. Overcoming the 90\% syndrome: Iteration management in concurrent development projects. Concurrent Engineering: Research and Applications, 111(3), pp. 177-186.

Forrester, J., 1961. Industrial Dynamics. Cambridge(MA): Productivity Press.

Forrester, J., 1985. The "model versus a modling process". System Dynamics Review, Volume 1, pp. 133-134.

Forrester, J., 1994. Policies, decisions, and information sources for modeling, In Morecroft, J. D. W., and Sterman, J. D. (Eds.), Modeling for Learning Organizations. Portland(OR): Productivity Press.

Garcia, J. M., 2006. Theory and practical exercises of system dynamics, Barcelona, Spain: Universitat Politecnica De Catalunya.

Golroudbary, S. R. \& Zahraee, S. M., 2015. System dynamics model for optimizing the recycling and collection of waste material in a closed-loop supply chain. Simulation Modelling Practice and Theory, Volume 53, pp. 88-102.

Graham, A. K., 2000. Beyond PM 101:lessons for managing large development programs. Project Management Journal, PMI, 31(4), pp. 7-18.

Hassan, M. M., 2009. Life-Cycle Assessment of Warm-Mix Asphalt: An Environmental and Economic Perspective. Washington, DC, s.n.

Huddleston, J., 2008. Sustainable Pavement Management Practices. Vancouver, WA, s.n.

ISI, 2015. Envision ${ }^{\mathrm{TM}}$ Sustainability Rating System. [Online]

Available at: http://www.sustainableinfrastructure.org/rating/

[Accessed 30 March 2015].

Jennings, N., Sycara, K. \& Woodridge, M., 1999. A roadmap of agent research and development. Autonomous Agents and Multi-Agent Systems, 1(1), pp. 7-38.

Joglekar, N. \& Ford, D. N., 2005. Product development resource allocation with foresight. European Journal of Operational Research, 160(1), pp. 72-87. 
Kandil, A., El-Rayes, K. \& El-Anwar, O., 2010. Optimization research: enhancing the robustness of large-scale multiobjective optimization in construction. Journal of Construction Engineering and Management, 136(1), pp. 17-25.

Larsen, D. A., 2003. Demonstration and Evaluation of SUPERPAVE Technologies, Final Evaluation Report for CT Route 2, Report No: 2219-F-02-7, Rocky Hill, CT: s.n.

Lee, S., Geum, Y., Lee, H. \& Park, Y., 2012. Dynamic and multidimensional measurement of product-service system (PSS) sustainability: a triple bottom line (TBL)-based system dynamics approach, Volume 32, pp. 173-182.

Lee, Z. W., Ford, D. N. \& Joglekar, N., 2007. Effects of Resource Allocation Policies for Reducing Project Durations: A Systems Modelling Approach. Systems Research and Behavioral Science, Volume 24, pp. 551-556.

Li, J., Sheng, Z. \& Liu, H., 2010. Multi-agent simulation for the dominant players' behavior in supply chains. Simulation Modelling Practice and Theory, Volume 18, pp. 850-859.

Lorenz, T. \& Jost, A., 2006. Towards an orientation framework in multi-paradigm modeling Aligning purpose, object and methodology in System Dynamics, Agent-based Modeling and Discrete-Event-Simulation. Nijmegen, The Netherlands, Proceedings of the 24th International Conference of the System Dynamics Society.

Lyneis, J. M., Cooper, K. G. \& Els, S. A., 2001. Strategic management of complex projects: a case study using system dynamics. System Dynamics Review, Volume 17, pp. 237-260.

Lyneis, J. M. \& Ford, D. N., 2007. System dynamics applied to project management: a survey, assessment, and directions for future research. System Dynamics Review, Volume 23, pp. 157-189.

Mladenovic, A., Turk, J., Kovac, J., Mauko, A. \& Cotic, Z., 2015. Environmental evaluation of two scenarios for the selection of materials for asphalt wearing courses. Journal of Cleaner Production, Volume 87, pp. 683-691.

NREL, 2012. U.S. Life Cycle Inventory Database, s.l.: National Renewable Energy Laboratory.

Ofori, G., 1992. The environment: the fourth construction project objective?. Construction Management and Economics, 10(5), pp. 369-395.

Ogunlana, S., Li, H. \& Sukhera, F., 2003. System dynamics approach to exploring performance enhancement in a construction organization. Journal of Construction Engineering and Management, 129(5), pp. 528-536. 
Ozcan-Deniz, G. \& Zhu, Y., 2011. A Systems Approach to Support the Selection of Highway Construction Operations with Environmental Concerns. Guangdong, China, Guangzhou University, Guangzhou.

Ozcan-Deniz, G. \& Zhu, Y., 2012. Evaluating construction methods for low carbon emissions using system dynamics modeling. ASCE.

Ozcan-Deniz, G. \& Zhu, Y., 2015. A Multi-Objective Decision-Support Model for Selecting Environmentally Conscious Highway Construction Methods. Journal of Civil Engineering and Management, 21(6), pp. 733-747.

Park, M. \& Pena-Mora, F., 2003. Dynamic change management for construction: Introducing the change cycle into model-based project management. System Dynamics Review, 19(3), pp. 213-242.

Ren, Z. \& Anumba, C. J., 2002. Learning in multi-agent systems: a case study of construction claims negotiation. Advanced Engineering Informatics, Volume 16, pp. 265-275.

Richardson, G. P. \& Pugh, A. L. I., 1981. Introduction to System Dynamics Modeling with Dynamo. Cambridge(MA): MIT Press.

Roberts, F., Mohammad, M. \& Wang, L., 2002. History of hot mix asphalt mixture design in the USA. Journal of Materials Civil Engineering, 14(4), pp. 279-293.

Rodrigues, A. \& Bowers, J., 1996. System dynamics in project management: a comparative analysis with traditional methods. System Dynamics Review, 12(1), pp. 121-139.

Rodrigues, A. G., 2001. Managing and modelling project risk dynamics: a system dynamicsbased framework. London, s.n.

Russell, M., Uhlmeyer, J. S., DeVol, J. \& Johnson, C., 2010. Evaluation of Hot In-Place Recycle, Report No. WA-RD 738.1, Olympia, WA: s.n.

Russell, S. \& Norvig, P., 2002. Artificial intelligence: A modern approach. 2nd ed. Upper Saddle River, NJ: Prentice-Hall.

Sahin, O., Stewart, R. A. \& Porter, M. G., 2015. Water security through scarcity pricing and reverse osmosis: a system dynamics approach. Journal of Cleaner Production, Volume 88, pp. 160-171.

Selih, J., 2007. Environmental management systems and construction SMES: a case study for Slovenia. Journal of Civil Engineering and Management, 13(3), pp. 217-226. 
Shen, L. Y., Wu, Y. Z., Chan, E. H. W. \& Hao, J. L., 2005. Application of system dynamics for assessment of sustainable performance of construction projects. Journal of Zhejiang University SCIENCE, 6A(4), pp. 339-349.

Shin, K., Lee, T. \& Kim, H., 2005. An application of support vector machines in bankruptcy prediction model. Expert Systems with Applications, 28(1), pp. 127-135.

Simon, H., 1996. The Sciences of the Artificial. Cambridge(MA): MIT Press.

Skorupka, D., 2008. Identification and initial risk assessment of construction projects in Poland. Journal of Management in Engineering, 24(3), pp. 120-127.

Sterman, J., 1992. System dynamics modeling for project management, Cambridge, MA: Massachusets Institute of Technology (MIT).

Sterman, J., 2000. Business dynamics: Systems thinking and modeling for a complex world. New York(NY): Irwin McGraw-Hill, pp. 83-133.

Terrel, R. L. \& Hicks, R. G., 2008. Viability of Hot In-Place Recycling as a Pavement Preservation Strategy, Chico, CA: s.n.

Thabrew, L., Wiek, A. \& Ries, R., 2009. Environmental decision making in multi-stakeholder contexts: applicability of life cycle thinking in development planning and implementation. Journal of Cleaner Production, Volume 17, pp. 67-76.

Tsai, W-H.; Lin, S-J.; Lee, Y-F.; Chang, Y-C.; Hsu, J-L., 2013. Construction method selection for green building projects to improve environmental sustainability by using an MCDM pproach. Journal of Environmental Planning and Management, 56(10), pp.1487-1510.

U.S.-DOE, 2007. Lifetime Cycle Inventory of Biodiesel and Petroleum Diesel for Use on an Urban Transit Bus, May 1998. [Online]

Available at:

http://kec.kansas.gov/chart_book/Chapter5/03_LifeCycleGHGEmissions.pdf [Accessed 30 March 2015].

Ugwu, O. O., Anumba, C. J. \& Thorpe, A., 2005. Ontological foundations for agent support in constructability assessment of steel structures-a case study. Automation in Construction, Volume 14, pp. 99-114.

Williams, T., 2002. Modelling Complex Projects. Chichester: Wiley.

Xue, X., Li, X., Shen, Q. \& Wang, Y., 2005. An agent-based framework for supply chain coordination in construction. Automation in Construction, Volume 14, pp. 413-430. 
Zhao, W., Ren, H. \& Rotter, V., 2011. A system dynamics model for evaluating the alternative of type in construction and demolition waste recycling center-The case of Chongqing, China. Resource, Conservation and Recycling, Volume 55, pp. 933-944. 


\section{A System Dynamics Model for Construction Method Selection under Sustainability Constraints}

Gulbin Ozcan-Deniz and Yimin Zhu

Tables

\section{Table 1}

System dynamics as applied in project management.

\section{Project management topics using SD Authors}

Poor schedule performance

(Abdel-Hamid, 1984); (Abdel-Hamid, 1988);

(Abdel-Hamid \& Madnick, 1991)

Concealing rework requirements for project (Ford \& Sterman, 2003a)

performance

The impacts of changes in the project scope

(Cooper, 1980); (Rodrigues \& Williams, 1997)

The effect of rework on the project (Cooper, 1993); (Ford, 1995); (Love, et al., performance 1999); (Lee, et al., 2006)

Failures in project fast track implementation

(Ford \& Sterman, 1998); (Ford \& Sterman, 2003b)

Construction firm performance

(Tang \& Ogunlana, 2003); (Ogunlana, et al., 2003)

The management of project contingencies

(Ford, 2002)

The planning of fast-track construction projects

(Pena-Mora \& Li, 2001); (Pena-Mora \& Park, 2001)

Construction innovation

(Park, et al., 2004)

Change management

(Park \& Pena-Mora, 2003); (Lee, et al., 2005);

(Lee, et al., 2006) 
Resource allocation

Managerial behavior in project performance

The role of tipping points in project (Taylor \& Ford, 2006); (Taylor \& Ford, 2008)

performance

The role of constructability reviews in project (Ford, et al., 2004)

schedule performance

Sustainable performance of projects
(Joglekar \& Ford, 2005); (Lee, et al., 2007)

(Ford \& Sterman, 2003a)

(Shen, et al., 2005b)

\section{Table 2}

Project conditions as defined in the decision-making process.

\begin{tabular}{cc}
\hline No & Project Conditions \\
\hline $\mathrm{C}_{1}$ & Adverse financial issues of owner \\
$\mathrm{C}_{2}$ & Adverse market conditions (affecting owner) \\
$\mathrm{C}_{3}$ & Change in the design \\
$\mathrm{C}_{4}$ & Unavailability of resources \\
$\mathrm{C}_{5}$ & Delay in resource delivery \\
$\mathrm{C}_{6}$ & Increase in the unit cost of resources \\
$\mathrm{C}_{7}$ & Unexpected conditions \\
\hline
\end{tabular}

\section{Table 3}

Construction methods as defined for resurfacing project activities.

\section{Construction Methods}

\begin{tabular}{llll} 
No & Resurfacing & Milling & Friction Course \\
\hline $\mathrm{CM}_{1}$ & Virgin-Conventional HMA & Conventional equipment & FC-5
\end{tabular}




\begin{tabular}{llll}
\hline $\mathrm{CM}_{2}$ & Virgin-Conventional HMA & Biodiesel equipment & FC-5 \\
$\mathrm{CM}_{3}$ & Recycled-Conventional HMA & Conventional equipment & FC-5 \\
$\mathrm{CM}_{4}$ & Recycled-Conventional HMA & Biodiesel equipment & FC-5 \\
$\mathrm{CM}_{5}$ & Virgin-WMA & Conventional equipment & FC-5 \\
$\mathrm{CM}_{6}$ & Superpave & Conventional equipment & FC-5 \\
$\mathrm{CM}_{7}$ & HIP Mix (Marshall+milled) & H.I.P.'s equipment & FC-5 \\
$\mathrm{CM}_{8}$ & HIP Mix (Marshall+milled) & HIP Biodiesel & FC-5 \\
$\mathrm{CM}_{9}$ & Virgin-Conventional HMA & Conventional equipment & FC-9,5 \\
$\mathrm{CM}_{10}$ & Virgin-Conventional HMA & Biodiesel equipment & FC-9,5 \\
$\mathrm{CM}_{11}$ & Recycled-Conventional HMA & Conventional equipment & FC-9,5 \\
$\mathrm{CM}_{12}$ & Recycled-Conventional HMA & Biodiesel equipment & FC-9,5 \\
$\mathrm{CM}_{13}$ & Virgin-WMA & Conventional equipment & FC-9,5 \\
$\mathrm{CM}_{14}$ & Superpave & Conventional equipment & FC-9,5 \\
$\mathrm{CM}_{15}$ & HIP Mix (Marshall+milled) & H.I.P.'s equipment & FC-9,5 \\
$\mathrm{CM}_{16}$ & HIP Mix (Marshall+milled) & HIP Biodiesel & FC-9,5 \\
\hline & & & \\
\hline
\end{tabular}

Table 4

Time, cost and environmental impact as calculated for Case Study 1.

\begin{tabular}{|c|c|c|c|c|c|c|}
\hline \multirow[t]{2}{*}{ No } & Material Type & $\begin{array}{c}\text { Crew\& } \\
\text { Equipment } \\
\text { Type }\end{array}$ & $\begin{array}{c}\text { Construction } \\
\text { Method }\end{array}$ & $\begin{array}{l}\text { Cost } \\
\text { Total }\end{array}$ & $\begin{array}{c}\text { Time } \\
\text { (days) }\end{array}$ & $\begin{array}{l}\text { GHG (kg } \\
\left.\mathrm{CO}_{2} \mathrm{Eq}\right)\end{array}$ \\
\hline & Resurfacing & Milling & $\begin{array}{l}\text { Friction } \\
\text { Course }\end{array}$ & & & \\
\hline $\mathrm{CM}_{1}$ & $\begin{array}{l}\text { Virgin- } \\
\text { Conventional } \\
\text { HMA }\end{array}$ & $\begin{array}{l}\text { Conventional } \\
\text { equipment }\end{array}$ & FC-5 layer & $\$ 1,959,429.07$ & 36 & $4,571,194.97$ \\
\hline $\mathrm{CM}_{2}$ & $\begin{array}{l}\text { Virgin- } \\
\text { Conventional } \\
\text { HMA }\end{array}$ & $\begin{array}{l}\text { Biodiesel } \\
\text { equipment }\end{array}$ & FC-5 layer & $\$ 1,996,200.07$ & 36 & $4,130,521.55$ \\
\hline
\end{tabular}




\begin{tabular}{|c|c|c|c|c|c|c|}
\hline $\mathrm{CM}_{3}$ & $\begin{array}{l}\text { Recycled- } \\
\text { Conventional } \\
\text { HMA }\end{array}$ & $\begin{array}{l}\text { Conventional } \\
\text { equipment }\end{array}$ & FC-5 layer & $\$ 1,794,123.80$ & 36 & $3,144,771.26$ \\
\hline $\mathrm{CM}_{4}$ & $\begin{array}{l}\text { Recycled- } \\
\text { Conventional } \\
\text { HMA }\end{array}$ & $\begin{array}{l}\text { Biodiesel } \\
\text { equipment }\end{array}$ & FC-5 layer & $\$ 1,830,894.80$ & 36 & $2,704,097.84$ \\
\hline $\mathrm{CM}_{5}$ & Virgin-WMA & $\begin{array}{l}\text { Conventional } \\
\text { equipment }\end{array}$ & FC-5 layer & $\$ 2,024,434.98$ & 36 & $4,481,971.64$ \\
\hline $\mathrm{CM}_{6}$ & Superpave & $\begin{array}{l}\text { Conventional } \\
\text { equipment }\end{array}$ & FC-5 layer & $\$ 1,945,751.89$ & 36 & $3,857,983.11$ \\
\hline $\mathrm{CM}_{7}$ & $\begin{array}{l}\text { HIP Mix } \\
\text { (Marshall+milled) }\end{array}$ & $\begin{array}{l}\text { H.I.P.'s } \\
\text { equipment }\end{array}$ & FC-5 layer & $\$ 1,356,935.27$ & 22 & $3,342,523.06$ \\
\hline $\mathrm{CM}_{8}$ & $\begin{array}{l}\text { HIP Mix } \\
\text { (Marshall+milled) }\end{array}$ & $\begin{array}{l}\text { HIP } \\
\text { Biodiesel }\end{array}$ & FC-5 layer & $\$ 1,363,662.60$ & 22 & $3,313,032.61$ \\
\hline $\mathrm{CM}_{9}$ & $\begin{array}{l}\text { Virgin- } \\
\text { Conventional } \\
\text { HMA }\end{array}$ & $\begin{array}{l}\text { Conventional } \\
\text { equipment }\end{array}$ & FC-9,5 layer & $\$ 1,961,275.87$ & 36 & $4,556,064.96$ \\
\hline $\mathrm{CM}_{10}$ & $\begin{array}{l}\text { Virgin- } \\
\text { Conventional } \\
\text { HMA }\end{array}$ & $\begin{array}{l}\text { Biodiesel } \\
\text { equipment }\end{array}$ & FC-9,5 layer & $\$ 1,998,046.87$ & 36 & $4,130,521.55$ \\
\hline $\mathrm{CM}_{11}$ & $\begin{array}{l}\text { Recycled- } \\
\text { Conventional } \\
\text { HMA }\end{array}$ & $\begin{array}{l}\text { Conventional } \\
\text { equipment }\end{array}$ & FC-9,5 layer & $\$ 1,795,970.60$ & 36 & $3,129,641.25$ \\
\hline $\mathrm{CM}_{12}$ & $\begin{array}{l}\text { Recycled- } \\
\text { Conventional } \\
\text { HMA }\end{array}$ & $\begin{array}{l}\text { Biodiesel } \\
\text { equipment }\end{array}$ & FC-9,5 layer & $\$ 1,832,741.60$ & 36 & $2,704,097.84$ \\
\hline $\mathrm{CM}_{13}$ & Virgin-WMA & $\begin{array}{l}\text { Conventional } \\
\text { equipment }\end{array}$ & FC-9,5 layer & $\$ 2,026,281.78$ & 36 & $4,466,841.63$ \\
\hline $\mathrm{CM}_{14}$ & Superpave & $\begin{array}{l}\text { Conventional } \\
\text { equipment }\end{array}$ & FC-9,5 layer & $\$ 1,947,598.69$ & 36 & $3,842,853.10$ \\
\hline $\mathrm{CM}_{15}$ & $\begin{array}{l}\text { HIP Mix } \\
\text { (Marshall+milled) }\end{array}$ & $\begin{array}{l}\text { H.I.P.'s } \\
\text { equipment }\end{array}$ & FC-9,5 layer & $\$ 1,358,782.07$ & 22 & $3,327,393.05$ \\
\hline $\mathrm{CM}_{16}$ & $\begin{array}{l}\text { HIP Mix } \\
\text { (Marshall+milled) }\end{array}$ & $\begin{array}{l}\text { HIP } \\
\text { Biodiesel }\end{array}$ & FC-9,5 layer & $\$ 1,365,509.40$ & 22 & $3,297,902.61$ \\
\hline
\end{tabular}

Table 5

Time, cost and environmental impact as calculated for Case Study 2.

\begin{tabular}{lllllll}
\hline No & Material Type & $\begin{array}{l}\text { Crew\& } \\
\text { Equipment } \\
\text { Type }\end{array}$ & $\begin{array}{l}\text { Construction } \\
\text { Method }\end{array}$ & $\begin{array}{l}\text { Cost } \\
\text { Total }\end{array}$ & $\begin{array}{l}\text { Time } \\
\text { (days) }\end{array}$ & $\begin{array}{l}\text { GHG (kg } \\
\text { CO2 Eq) }\end{array}$ \\
& Resurfacing & Milling & $\begin{array}{l}\text { Friction } \\
\text { Course }\end{array}$ & & & \\
\hline $\mathrm{CM}_{1}$ & $\begin{array}{l}\text { Virgin- } \\
\text { Conventional }\end{array}$ & $\begin{array}{l}\text { Conventional } \\
\text { equipment }\end{array}$ & FC-5 layer & $\$ 1,154,345.6$ & 29 & $2,479,200.38$ \\
& HMA & Biodiesel & FC-5 layer & $\$ 1,166,383.9$ & 29 & $2,374,531.37$ \\
$\mathrm{CM}_{2}$ & $\begin{array}{l}\text { Virgin- } \\
\text { Conventional }\end{array}$ & $\begin{array}{l}\text { equipment } \\
\end{array}$ & & 7 & &
\end{tabular}


HMA

\begin{tabular}{|c|c|c|c|c|c|c|}
\hline $\mathrm{CM}_{3}$ & $\begin{array}{l}\text { Recycled- } \\
\text { Conventional } \\
\text { HMA }\end{array}$ & $\begin{array}{l}\text { Conventional } \\
\text { equipment }\end{array}$ & FC-5 layer & $\begin{array}{l}\$ 1,026,810.8 \\
2\end{array}$ & 29 & $1,601,590.78$ \\
\hline $\mathrm{CM}_{4}$ & $\begin{array}{l}\text { Recycled- } \\
\text { Conventional } \\
\text { HMA }\end{array}$ & $\begin{array}{l}\text { Biodiesel } \\
\text { equipment }\end{array}$ & FC-5 layer & $\begin{array}{l}\$ 1,038,849.1 \\
9\end{array}$ & 29 & $1,496,921.77$ \\
\hline $\mathrm{CM}_{5}$ & Virgin-WMA & $\begin{array}{l}\text { Conventional } \\
\text { equipment }\end{array}$ & FC-5 layer & $\begin{array}{l}\$ 1,204,518.3 \\
2\end{array}$ & 29 & $2,424,305.57$ \\
\hline $\mathrm{CM}_{6}$ & Superpave & $\begin{array}{l}\text { Conventional } \\
\text { equipment }\end{array}$ & FC-5 layer & $\begin{array}{l}\$ 1,143,767.6 \\
0\end{array}$ & 29 & $2,040,395.58$ \\
\hline $\mathrm{CM}_{7}$ & $\begin{array}{l}\text { HIP Mix } \\
\text { (Marshall+milled) }\end{array}$ & $\begin{array}{l}\text { H.I.P.'s } \\
\text { equipment }\end{array}$ & FC-5 layer & $\$ 774,203.12$ & 19 & $1,822,616.88$ \\
\hline $\mathrm{CM}_{8}$ & $\begin{array}{l}\text { HIP Mix } \\
\text { (Marshall+milled) }\end{array}$ & $\begin{array}{l}\text { HIP } \\
\text { Biodiesel }\end{array}$ & FC-5 layer & $\$ 778,342.13$ & 19 & $1,804,472.85$ \\
\hline $\mathrm{CM}_{9}$ & $\begin{array}{l}\text { Virgin- } \\
\text { Conventional } \\
\text { HMA }\end{array}$ & $\begin{array}{l}\text { Conventional } \\
\text { equipment }\end{array}$ & FC-9,5 layer & $\begin{array}{l}\$ 1,156,684.1 \\
0\end{array}$ & 29 & $2,476,160.92$ \\
\hline $\mathrm{CM}_{10}$ & $\begin{array}{l}\text { Virgin- } \\
\text { Conventional } \\
\text { HMA }\end{array}$ & $\begin{array}{l}\text { Biodiesel } \\
\text { equipment }\end{array}$ & FC-9,5 layer & $\begin{array}{l}\$ 1,168,722.4 \\
7\end{array}$ & 29 & $2,374,531.37$ \\
\hline $\mathrm{CM}_{11}$ & $\begin{array}{l}\text { Recycled- } \\
\text { Conventional } \\
\text { HMA }\end{array}$ & $\begin{array}{l}\text { Conventional } \\
\text { equipment }\end{array}$ & FC-9,5 layer & $\begin{array}{l}\$ 1,029,149.3 \\
2\end{array}$ & 29 & $1,598,551.32$ \\
\hline $\mathrm{CM}_{12}$ & $\begin{array}{l}\text { Recycled- } \\
\text { Conventional } \\
\text { HMA }\end{array}$ & $\begin{array}{l}\text { Biodiesel } \\
\text { equipment }\end{array}$ & FC-9,5 layer & $\begin{array}{l}\$ 1,041,187.6 \\
9\end{array}$ & 29 & $1,496,921.77$ \\
\hline $\mathrm{CM}_{13}$ & Virgin-WMA & $\begin{array}{l}\text { Conventional } \\
\text { equipment }\end{array}$ & FC-9,5 layer & $\begin{array}{l}\$ 1,206,856.8 \\
2\end{array}$ & 29 & $2,421,266.12$ \\
\hline $\mathrm{CM}_{14}$ & Superpave & $\begin{array}{l}\text { Conventional } \\
\text { equipment }\end{array}$ & FC-9,5 layer & $\begin{array}{l}\$ 1,146,106.1 \\
0\end{array}$ & 29 & $2,037,356.12$ \\
\hline $\mathrm{CM}_{15}$ & $\begin{array}{l}\text { HIP Mix } \\
\text { (Marshall+milled) }\end{array}$ & $\begin{array}{l}\text { H.I.P.'s } \\
\text { equipment }\end{array}$ & FC-9,5 layer & $\$ 776,541.62$ & 19 & $1,819,577.42$ \\
\hline $\mathrm{CM}_{16}$ & $\begin{array}{l}\text { HIP Mix } \\
\text { (Marshall+milled) }\end{array}$ & $\begin{array}{l}\text { HIP } \\
\text { Biodiesel }\end{array}$ & FC-9,5 layer & $\$ 780,680.63$ & 19 & $1,801,433.40$ \\
\hline
\end{tabular}

\section{Table 6}

Time, cost, and GHG results given as an example set.

\begin{tabular}{llll}
\hline Case Study 1 & Project Time & Project Cost & Project GHG \\
\hline $\mathrm{CM}_{13}$ & 36 & $\$ 2,026,281.78$ & $4,466,841.63$ \\
\hline
\end{tabular}

\section{Table 7}

Input and output values as resulted from Case Study 1. 


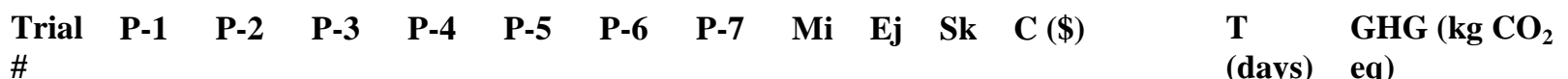
$\begin{array}{llll}\# & \text { (days) eq) }\end{array}$

\begin{tabular}{rrrrrrrrrrrrrr}
\hline 1 & 0.63 & 0.61 & 0.35 & 0.51 & 0.99 & 0.10 & 0.27 & 4 & 1 & 1 & $1,945,751.89$ & 36 & $3,857,983.11$ \\
2 & 0.63 & 0.44 & 0.98 & 0.62 & 0.67 & 0.88 & 0.17 & 4 & 1 & 1 & $1,945,751.89$ & 36 & $3,857,983.11$ \\
3 & 0.17 & 0.00 & 0.49 & 0.38 & 0.63 & 0.80 & 0.80 & 1 & 2 & 2 & $1,998,046.87$ & 36 & $4,130,521.55$ \\
4 & 0.74 & 0.27 & 0.14 & 0.15 & 0.95 & 0.49 & 0.48 & 2 & 2 & 1 & $1,830,894.80$ & 36 & $2,704,097.84$ \\
5 & 0.70 & 0.44 & 0.00 & 0.64 & 0.70 & 0.16 & 0.27 & 2 & 2 & 1 & $1,830,894.80$ & 36 & $2,704,097.84$ \\
6 & 0.63 & 0.10 & 0.71 & 0.98 & 0.12 & 0.43 & 0.97 & 2 & 2 & 2 & $1,832,741.60$ & 36 & $2,704,097.84$ \\
7 & 0.15 & 0.09 & 0.55 & 0.42 & 0.31 & 0.42 & 0.37 & 1 & 1 & 2 & $1,961,275.87$ & 36 & $4,556,064.96$ \\
8 & 0.83 & 0.21 & 0.95 & 0.31 & 0.18 & 0.35 & 0.75 & 2 & 2 & 2 & $1,832,741.60$ & 36 & $2,704,097.84$ \\
9 & 0.45 & 0.46 & 0.99 & 0.05 & 0.74 & 0.55 & 0.80 & 2 & 2 & 2 & $1,832,741.60$ & 36 & $2,704,097.84$ \\
10 & 0.01 & 0.83 & 0.85 & 0.89 & 0.80 & 0.72 & 0.64 & 4 & 1 & 1 & $1,945,751.89$ & 36 & $3,857,983.11$ \\
11 & 0.76 & 0.53 & 0.56 & 0.98 & 1.00 & 0.91 & 0.78 & 5 & 4 & 1 & $1,363,662.60$ & 22 & $3,313,032.61$ \\
12 & 0.86 & 0.80 & 0.98 & 0.70 & 0.83 & 0.96 & 0.80 & 5 & 4 & 1 & $1,363,662.60$ & 22 & $3,313,032.61$ \\
13 & 0.67 & 0.02 & 0.28 & 0.09 & 0.44 & 0.35 & 0.08 & 1 & 1 & 2 & $1,961,275.87$ & 36 & $4,556,064.96$ \\
14 & 0.15 & 0.10 & 0.40 & 0.05 & 0.10 & 0.15 & 0.40 & 3 & 1 & 2 & $2,026,281.78$ & 36 & $4,466,841.63$ \\
15 & 0.10 & 0.05 & 0.35 & 0.02 & 0.02 & 0.20 & 0.50 & 3 & 1 & 2 & $2,026,281.78$ & 36 & $4,466,841.63$ \\
16 & 0.01 & 0.76 & 0.29 & 0.41 & 0.75 & 0.12 & 0.80 & 2 & 2 & 2 & $1,832,741.60$ & 36 & $2,704,097.84$ \\
17 & 0.67 & 0.51 & 0.22 & 0.27 & 0.97 & 0.33 & 0.79 & 4 & 1 & 1 & $1,945,751.89$ & 36 & $3,857,983.11$ \\
18 & 0.27 & 0.23 & 0.02 & 0.63 & 0.01 & 0.63 & 0.07 & 1 & 1 & 2 & $1,961,275.87$ & 36 & $4,556,064.96$ \\
19 & 0 & 0 & 0 & 0 & 0 & 0 & 0 & 3 & 1 & 2 & $2,026,281.78$ & 36 & $4,466,841.63$ \\
20 & 1 & 1 & 1 & 1 & 1 & 1 & 1 & 5 & 4 & 1 & $1,363,662.60$ & 22 & $3,313,032.61$ \\
\hline
\end{tabular}




\section{A System Dynamics Model for Construction Method Selection under Sustainability Constraints}

Gulbin Ozcan-Deniz and Yimin Zhu

\section{Figures}

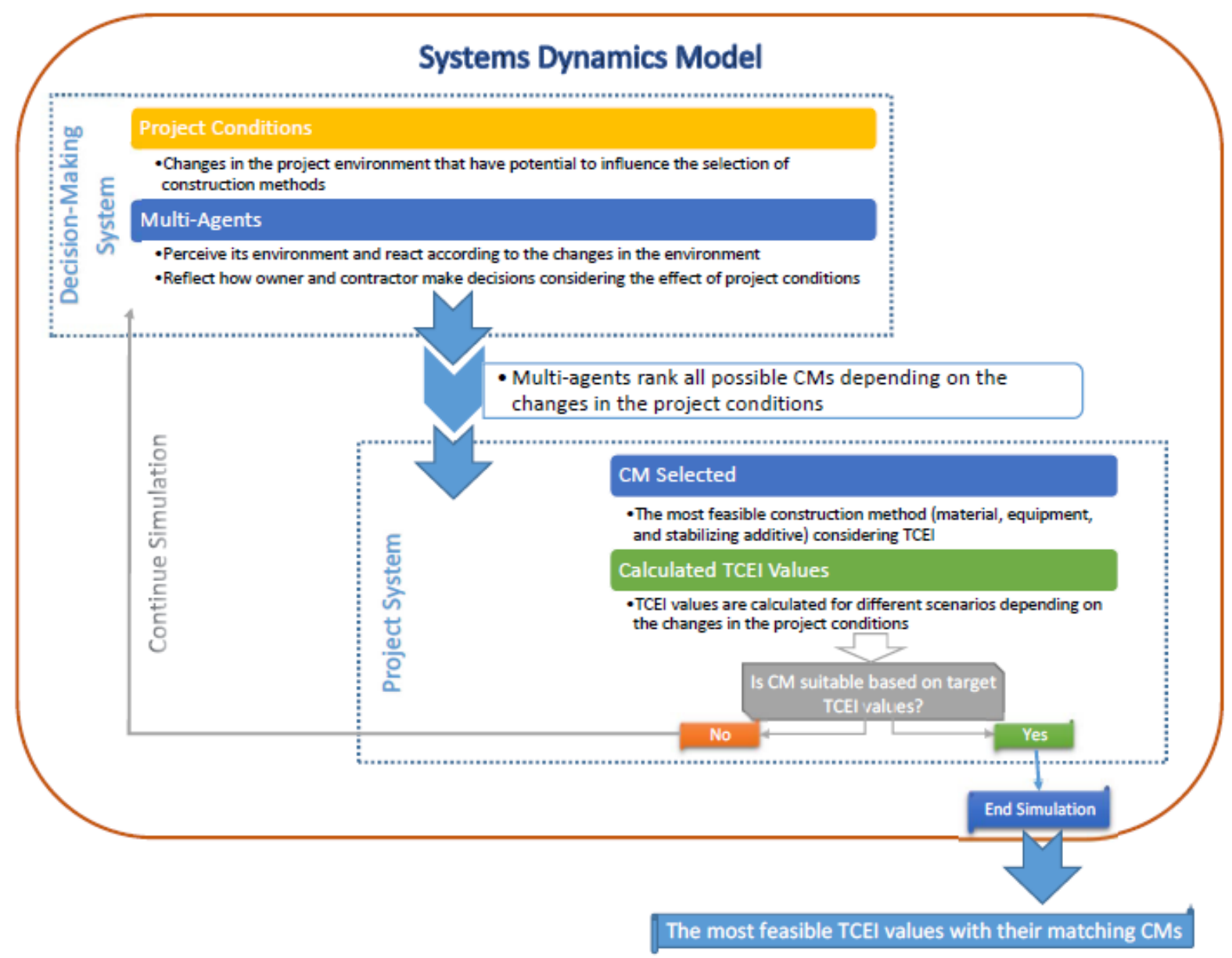

Fig. 1. Conceptual model as created for the construction system. 


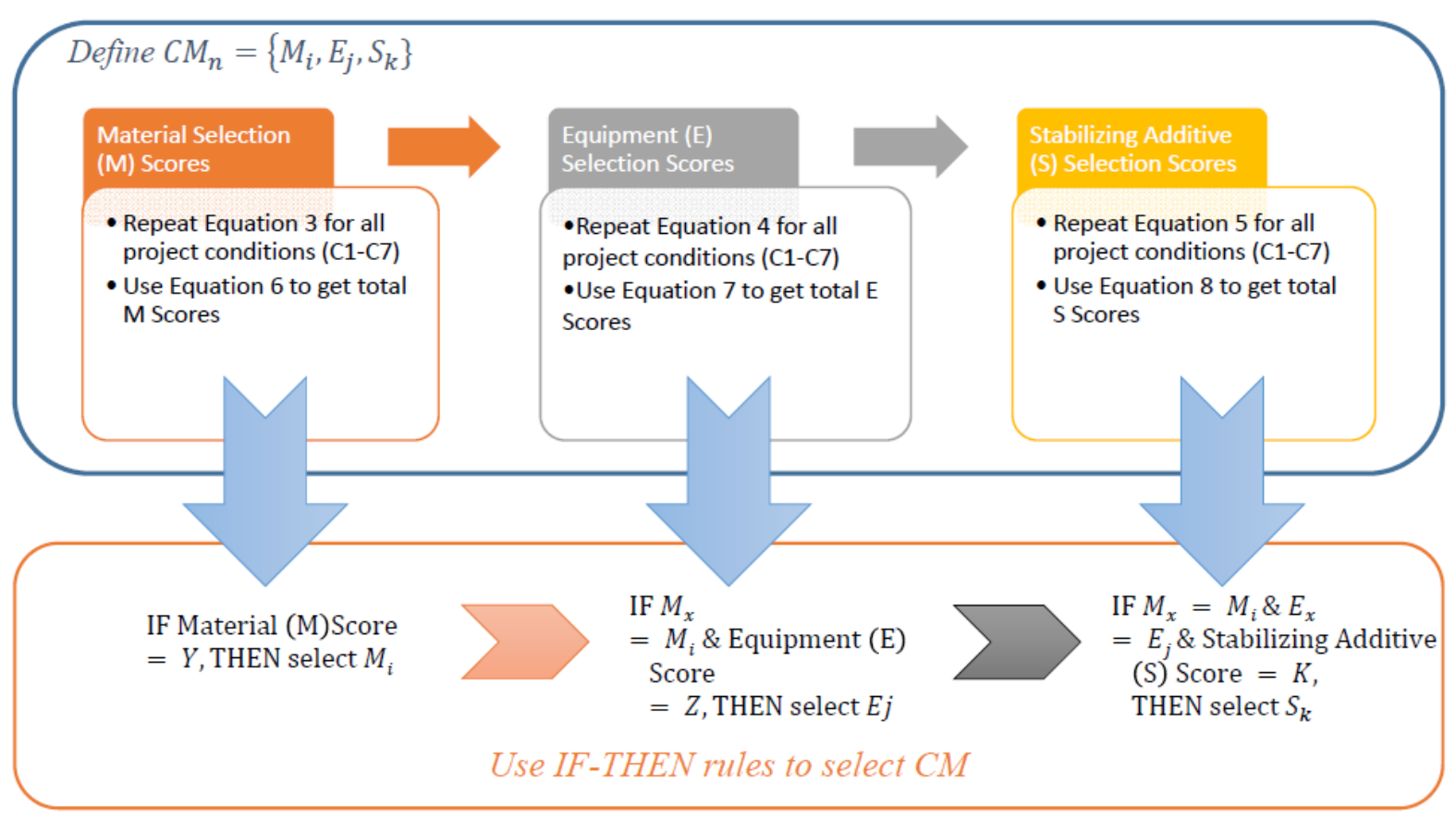

Fig. 2 Flowchart to perform decision-making.

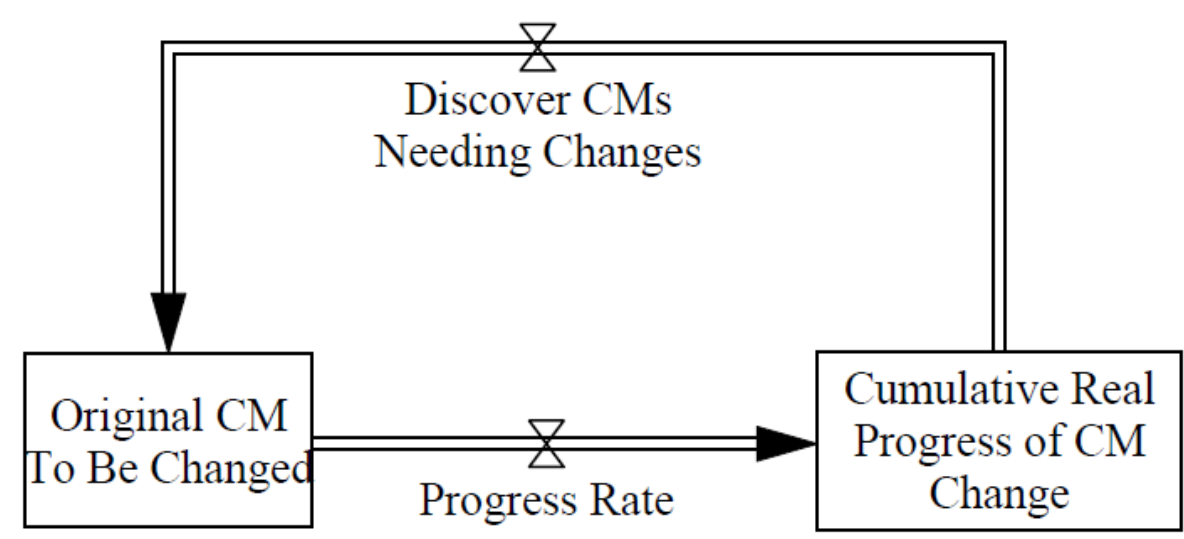

Fig. 3 Rework cycle as run in the SD simulation. 


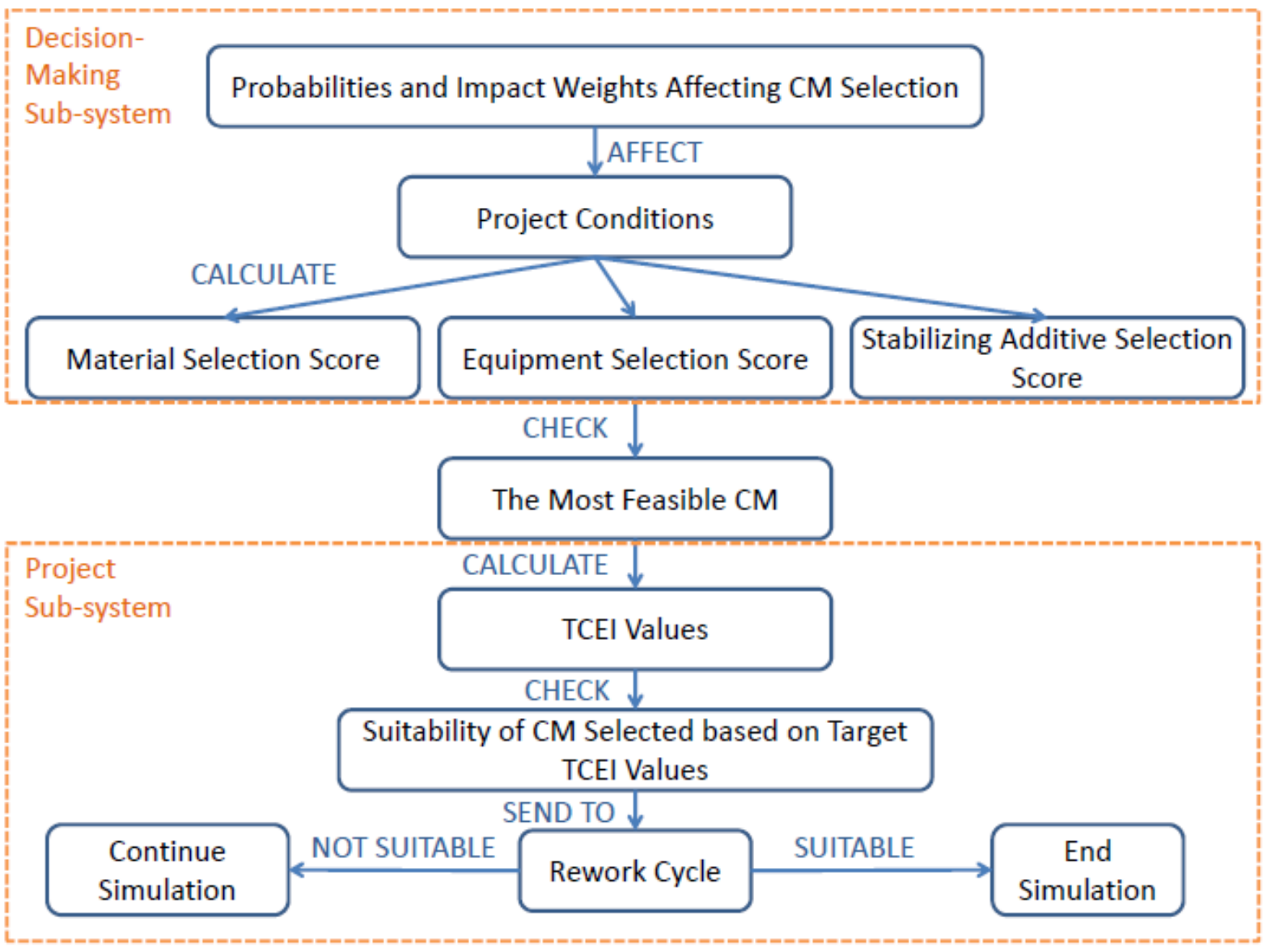

Fig. 4 Flowchart as created for the proposed SD model. 


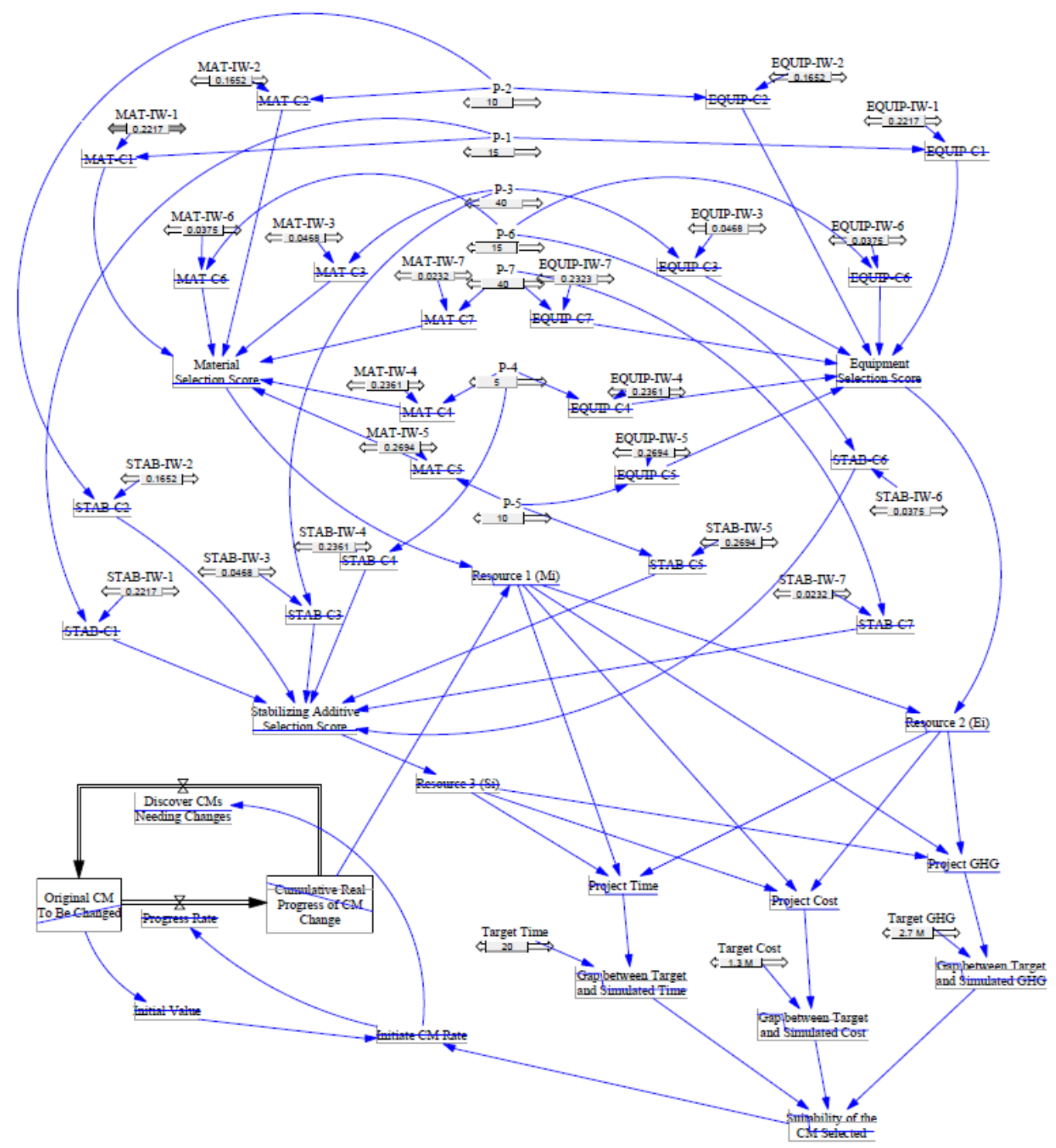

Fig. 5. Vensim screen as seen during the simulation. 